\title{
Failure Probability of Mining Slope Recommendation at Asphalt Mine, Buton, South East Sulawesi
}

\author{
Bayurohman Pangacella Putra ${ }^{1}$, Novandri Kusuma Wardhana ${ }^{1}$ \\ \{bayurohman@itny.ac.id\} \\ Institut Teknologi Nasional Yogyakarta, Caturtunggal, Depok, Sleman, D.I.Yogyakarta, Indonesia ${ }^{1,2}$
}

\begin{abstract}
Ministerial Decree No $1827 \mathrm{~K} / 30 / \mathrm{MEM} / 208$ states that mine geotechnics should inclose mining slope's probability of failure $(\mathrm{PoF})$ value, beside safety factor (SF), to express a degree stability. PoF tolerances are associated with the risk of consequence when the slope failures. This regulation conforms with geological uncertainty commonly encountered at asphalt mining industry. Overall asphalt mining highwall that is constituted by layers of sedimentary rocks subject to variation of its geotechnical parameters value. Required rock characteristics of Mohr-Coulomb's failure Criteria, i.e. cohesion and internal friction angle were statistically analysis to map their probability distributions. Numerical analysis is then carried out to determine slope's PoF for several slope dips and then followed with correlation and regression analysis. Correlation analysis indicates that PoF value rises as the slope dips steeper. Regression analysis results that overall slope dip recommendations are $48^{\circ}, 55^{\circ}$, and $62.5^{\circ}$ for high, moderate, and low failure consequence respectively. Considering mineable reserve conservation, steeper slope would not be recommended.
\end{abstract}

Keywords: Mining Slope, Asphalt Mine

\section{Introduction}

Surface mining operation always face slope stability problems. So do asphalt mine that operates in Buton, South East Sulawesi, Indonesia. Mining slope in asphalt mine is constitued by layers of sedimetary rocks, such as mudstone, siltstone, and sandstone beside asphalt seam as can be seen in sectional area of asphalt mining slope at Figure 1 (Duwila, 2017). Since asphalt exploitation is still advancing, recommendation of mining slope geometry is needed to ensure the safety working environment and the production continuity.

Recommendation of slope geometry is based on its stability quantification. Beside safety factors (SF), attention to probability of failure $(\mathrm{PoF})$ arises. University research about probability of failure is unceasing that is indicated by Doctorate University of Alberta in Canada (El-Ramy, Morgensten and Cruden, 2002). Slope geometry recommendation based on probability of failure utilizes variability of rock mass characteristics that constitute the slope. Probability of Failure can be assessed by seeing SF value distribution that is shaped as the result of combinations of rock mass engineering characteristics.

Ministerial Decree issued by Ministry of Energy and Mineral Resources of Republic of Indonesia No 1827 K/30/MEM/2018 about Guideline of Good Mining Practice, article about feasibility study states that mining geotechnics should include probability of failure value in their documents beside the design of the slope models. So, this article is made to give the slope geometry recommendation that can satisfy the criteria on the regulation. 


\section{Methodology}

Methodology of the research can be seen as a flow chart in Figure 2. Rock mass characteristics are collected laboratorium test conducted and summarized for a thesis by Duwila (2017). Topography map, rocks distribution, cross sections, and water table elevations are also collected from company's archives.

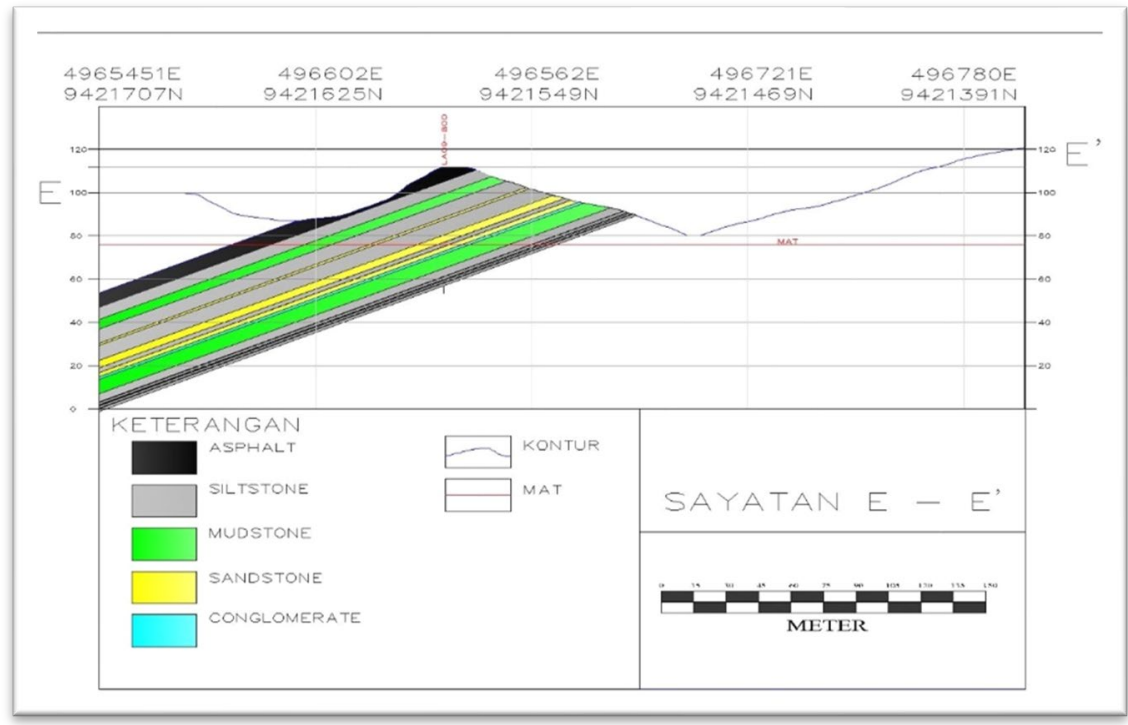

Fig. 1. Cross section E-E' of asphalt mine, Buton, South East Sulawesi

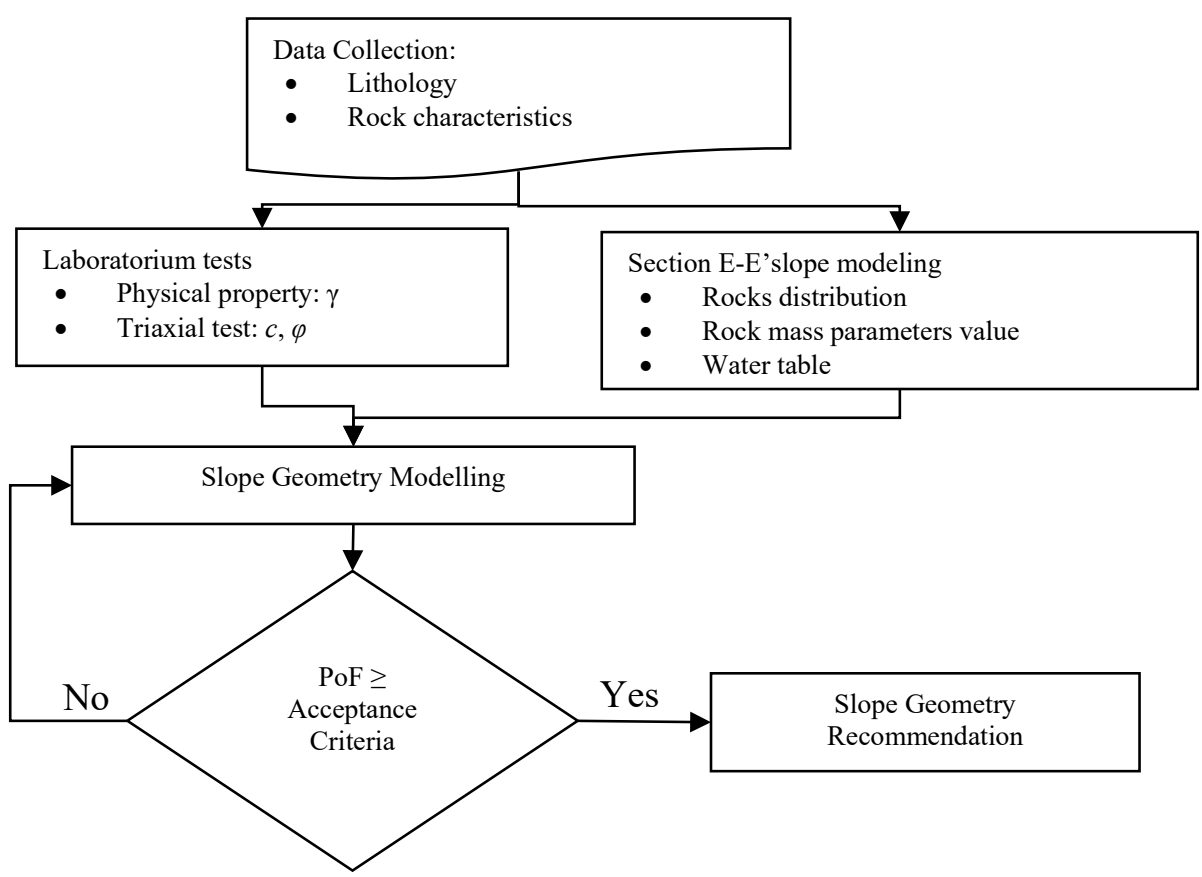


Fig. 2. Analysis flow chart

Safety Factor and Probability of Failure are calculated using Mohr-Coulomb's failure criteria. The slope geometry that is recommended is one whose Probability of Failure satisfies acceptance criteria stated in Ministerial Decree No 1827 K/30/MEM/2018 (Table 1). Acceptance criterion are based on consequence of failure. Consequence of failure can be interpreted as how high the cost would be paid to remediate the impact. Should the cost higher, the consequence also higher and it is indicated by the PoF with lower tolerance. During mining project, consequence of failure changes depending on the slope importance. Working face and hauling road is considered more important than abandoned or disposal slope since fatality, injury, damage of equipment and closed hauling access could occur.

The variation value of Mohr-Coulomb's rock parameters i.e. cohesion (c) and internal friction angle $(\Phi)$ are needed. Their values are processed statistically to produce their mean, minimal, maximum, and standard deviation value. Those values would be entered as input data into the numerical program to calculate the probability of failure. Combinations of value of two parameters yields a variety of FS values. Ratio of FS values under 1 with all possible FS values is known as PoF. Illustration that depicts SF and PoF from two variables cohesion and internal friction angle can be seen in Figure 3.

Overall slope stability would be evaluated at several value of its dip. Recommended slope geometry is the ones that give PoF lower than acceptance criteria stated in the Ministerial Decree. As the consequence of failure is a subject to change, more than one slope geometries could be suggested for one slope section. Graphical output would be presented and regression formula would be provided to understand the maximum limit of slope geometry for each level of consequence of failure.

\subsection{Slope model and failure mode approach}


Slope model is based on sectional area of mining pit Section E-E'. Mining slope is constituted by prementioned rock layers that dip gently which can be seen at Figure 1. High wall of the mining pit would dip against the layer's dip direction. SF and FoF would be determine on the highwall side of the mining slope.

Considering there are bedding planes between each rock layers, rock slides as plane failure with those bedding plane act as weakness plane where the rocks sliding on. This type of noncircular failure surface is taken as the failure mode to calculate the SF and PoF values of the asphalt mining overall slope.

\subsection{Rock characterstics}

For analitical purpose, laboratorium test of rock charateristics are needed. Physical properties test and direct shear test was carried out to determine density $(\gamma)$, cohesion $(c)$, and internal friction angle $(\Phi)$. There are four kinds of rock to be tested, e.g. sandstone, mudstone, siltstone, and asphalt. The laboratorium tests result of geotechical parameters mean value can be seen at Table 2 .

As stated before, the variety of rock parameter values are processed statistically. Two parameters from Mohr-Coulomb's failure criteria, cohesion $(c)$ and internal friction angle $(\Phi)$ values of each rock are modeled so they have some required descriptive statistics parameters such as mean value, standard deviation, minimum and maximum value. To give estimation of parameter variability values around mean symmetrically, not skewed toward the bigger or the lesser value, both parameters are considered normally distributed. Rocks density is left fixed at only one value, as it is not a Mohr-Coulomb's failure criteria variable.

\section{Results}

Results of numerical calculation using Mohr-Coulomb's failure criteria can be seen at Figure 3 - Figure 7 and are summarized in Table 3. Numerical calculation indicates that the PoF value rises as the overall slope angle decreases. At overall slope angle $80^{\circ}, \mathrm{PoF}$ is $46.1 \%$. Meanwhile, at overall slope angle $70^{\circ}, \mathrm{PoF}$ is $59.7 \%$. Both of these values of PoF are above acceptance level even for low risk consequence of failure. Thus, overall slope that dips $70^{\circ}$ or greater is not recommended for section E-E'.

Decreasing overall slope angle to $60^{\circ}, 50^{\circ}$, and $40^{\circ}$, the corresponding PoF are $19.9 \%, 5.5 \%$, and $1.7 \%$ respectively. From these three results, one can see that for low risk consequence, overall slope with dips $60^{\circ}$ is acceptable. Meanwhile for medium risk consequence, overall slope with dips $50^{\circ}$ is acceptable, and for high risk consequence, overall slope with dips $40^{\circ}$ is acceptable.

Table 1. PoF classification by slope's consequence of failure (Ministry of Energy and Mineral Resources of Republic of Indonesia No 1827 K/30/MEM/2018)

\begin{tabular}{|c|c|c|c|c|}
\hline \multirow[b]{2}{*}{ Slope type } & \multirow{2}{*}{$\begin{array}{l}\text { Consequences of } \\
\text { Failure }\end{array}$} & \multicolumn{3}{|c|}{ Acceptance Criteria } \\
\hline & & $\begin{array}{c}\text { Static Safety } \\
\text { Factor (SF) }\end{array}$ & $\begin{array}{c}\text { Dinamic Safety } \\
\text { Factor (SF) }\end{array}$ & $\begin{array}{l}\text { Probability of } \\
\text { Failure (PoF) }\end{array}$ \\
\hline Single Slope & Medium to High & 1.1 & N/A & $25-50 \%$ \\
\hline \multirow{3}{*}{ Inter-ramp } & Low & $1.15-1.2$ & 1.0 & $25 \%$ \\
\hline & Moderate & $1.2-1.3$ & 1.0 & $20 \%$ \\
\hline & High & $1.2-1.3$ & 1.1 & $10 \%$ \\
\hline \multirow{3}{*}{$\begin{array}{l}\text { Overall } \\
\text { Slope }\end{array}$} & Low & $1.2-1.3$ & 1.0 & $15-20 \%$ \\
\hline & Moderate & 1.3 & 1.05 & $10 \%$ \\
\hline & High & $1.3-1.5$ & 1.1 & $5 \%$ \\
\hline
\end{tabular}


Table 2. Mean Value of Rock Mass Characteristics

\begin{tabular}{ccrccr}
\hline & $\begin{array}{c}\text { Density } \\
\left(\mathrm{MN} / \mathrm{m}^{3}\right)\end{array}$ & $\sigma_{c i}(\mathrm{MPa})$ & $c(\mathrm{MPa})$ & $\Phi\left(^{\circ}\right)$ & $\sigma_{t}(\mathrm{MPa})$ \\
\cline { 2 - 6 } & 0,0156 & 0,575847 & 0,080712 & 26,3176 & $-0,00175$ \\
Asphalt & 0,0192 & 3,25 & 0,075424 & 17,4773 & $-0,00903$ \\
Mudstone & 0,0157 & 161,688 & 0,105107 & 28,2864 & $-0,01208$ \\
Siltstone & 0,0166 & 235,244 & 0,180389 & 38,9621 & $-0,01306$ \\
Sandstone & 0,0176 & 210,915 & 0,145602 & 31,5389 & $-0,02471$ \\
Siltstone & 0,0196 & 345,999 & 0,114428 & 23,6302 & $-0,03441$ \\
Mudstone & & & & & \\
\hline
\end{tabular}

To optimize the mineable reserve, slope geometries that give boundary value of PoF in each level of risk are needed to be determined. Slope angles at each level of risk consequence of failure limit can be calculated by correlation and regression analysis (Figure 8). Correlation analysis indicated that slope dip has positive relation with PoF value and the regression model could describe $94.05 \%$ of parameter value variations.

Using PoF values from each modeled overall slope angles, power regression depicts that PoF is a function of overall slope angle which satisfies $\mathrm{PoF}=6.10^{-9}$ (Overall Slope Angle $)^{5.302}$. Graphical output from regression and analysis can be seen at Figure 9.

Roof limit of PoF are 5\%,10\%, and 20\% for high, moderate, and low consequence of failure. When risks of failure consequence are high, the asphalt mining overall slope could be constructed to dip $48^{\circ}$. For moderate risks, slope dip could be steeper up to $55^{\circ}$. For low risks, mining overall slope could be constructed to dip $62.5^{\circ}$. Any steeper, PoF value would pass beyond acceptance criteria, thus unrecommendable.

\section{Conclusions}

Should consequence of failure higher, tolerance of PoF value would be lower. Asphalt mining Slope with high risks of failure consequence needs to have slope dip only up to $48^{\circ}$. For moderate risks, slope dip could be steeper up to $55^{\circ}$. While For low risks, mining overall slope could be steeper up to $62.5^{\circ}$. Mining with slope dip any steeper would not be acceptable in optimization context.

\section{Acknowledgement.}

Authors wishing to acknowledge fund, assistance, and encouragement from ITNY and PT. Kurnia Alam Indonesia for the opportunity to take data of the asphalt mining activities, as well as Ikhwan Duwila, S.T. who researched in the site.

\section{References}

[1] Duwila, K. I., 2017. Rock Mass Strength Analysis Based on Laboratory Test and Gelogical Structure Analysis at PT. Karuni Alam Indonesia Lasalimu Subdistrict, Buton District, South East Sulawesi Province. Bacheloral Thesis, Sekolah Tinggi Teknologi Nasional, Yogyakarta

[2] Hoek, E. Bray, J.W. 1981. Rock Slope Engineering 3rd Edition. Institution of Mining and Metalurgy London

[3] Barton, N.R., 1973, Review of a New Strength Criterion for Rock Joint, Engineering Geology, Elsevier. 
[4] Barton, N.R., and Chobey, V., 1977, The Shear of Rock Joint in Theory and Practice, Rock Mechanic

[5] Bieniawski, Z.T., 1989, Engineering Slope Rock Mass Classifications, John Wiley and Sons, Canada

[6] Cunha, P.A., 1990, Scale Effect in Rock Masses, Proc. The 1 st intl. Workshop on Scale Effects in Rock Massees, Edited by cunha , Norway.

[7] Gabrielsen, R. H.,1990,Characteristics of Joints and Faults. Proceedings of the International Symposium on Rock Joint, Loen, Norway. N. Bartonand O. Stephansson (eds). Balkema, Rotterdam.

[8] Goodman, R.E., and Bray,J.W., 1976, Toppling of Rock Slope, Proc. Specialty Conference on Rock Engineering for Foundation and Slope, Colorado.

[9] Hoek, E., 2000,Practical Rock Engineering, Rockscience, London

[10] Hoek, E., and Bray, J.W., 1981, Rock Slope Engineering, 3th Edition, Civil And Mining4th Edition, London.

[11] Hoek, E., and Brown, E.T., 2002, A Brief History of The Development of The Hoek-Brown failure criterion, Acessed Trought The Program Roclab.

[12] Jaeger, J.C., and Cook, N.G.W., 1976, Fundamentals ofRock Mechanics, 2nd ed., Chapman and Hall, London.

Kenney, T.C., 1967, The Influence of Mineral Composition on The Residual Strength of Natural Soils., Procceding. Geotechnical Conference, Oslo, Norway.

[14] Palmstrom, A., 1995,A Rock Mass Characterization System For Rock Engineering Purposes, PhD Thesis, Oslo University, Norway.

[15] Palmstrom, A., 1995,A Rock Mass Characterization System For Rock Engineering Purposes, PhD Thesis, Oslo University, Norway.

[16] Patton, F.D., 1966, Multiple Modes Of Shear Failure In Rock, Cong Rock Mech, Lisbon.

[17] Saptono, S., 2012, Pengembangan Metode Analisis Stabilitas Lereng Berdasarkan Karakteristik Batuan Ditambang Batubara Terbuka, Institut Teknologi Bandung, Bandung.

[18] Sikumbang, N.,Sanyoto, P., Supandjono,R. J. B., 1995, Peta Geologi Lembar Buton, Sulawesi Tenggara Skala 1:250.000, Pusat Penelitian dan Pengembangan Geologi, Bandung.

[19] Das, B. M., 1995,. Mekanika Tanah (Prinsip-prinsip Rekayasa Geoteknis). The University of Texas, El Paso. 